\title{
DISTRIBUIÇÃO ESPACIAL DE Sitophilus zeamais (Coleoptera: Curculionidae) E Oryzaephilus surinamensis (Col.: Silvanidae) EM ESTRUTURA ARMAZENADORA CONTENDO MILHO
}

\section{SPATIAL DISTRIBUTION OF Sitophilus zeamais (Coleoptera: Curculionidae) AND Oryzaephilus surinamensis (Col.: Silvanidae) IN A CORN STORAGE FACILITY}

\author{
Fabiane Cristina CERUTI ${ }^{1}$ \\ Airton Rodrigues PINTO JR. ${ }^{2}$
}

\begin{abstract}
RESUMO
Neste trabalho é discutida a distribuição espacial dos coleópteros de grãos armazenados Sitophilus zeamais (Coleoptera: Curculionidae) e Oryzaephilus surinamensis (Coleoptera: Silvanidae) coletados em armazém graneleiro de milho, incluindo as áreas de recebimento e secagem, durante o período de agosto de 2001 a junho de 2002 em Videira - SC. No experimento empregaram-se 20 armadilhas tipo gaiola com isca alimentar, distribuídas na estrutura armazenadora, para detectar os focos de insetos. Durante as coletas 76.931 coleópteros foram capturados nas armadilhas. As espécies encontradas em maior número foram: 0 . surinamensis $(92 \%)$ e $S$. zeamais $(7 \%)$ consideradas pragas secundária e primária de grãos armazenados respectivamente. Mensalmente foi determinada a distribuição espacial dos insetos coletados e representada em gráficos de distribuição sazonal (quatro estações do ano) usando o programa Surfer ${ }^{\circledR}$. Nos mapas de distribuição espacial do número de insetos, observou-se infestação de $S$. zeamais nas áreas distais às células de armazenamento e infestações elevadas de $O$. surinamensis, nas áreas próximais às células de armazenamento e no túnel do graneleiro. Desta forma, o monitoramento com armadilhas do tipo gaiola, representa uma ferramenta indispensável para a detecção prévia das populações de insetos nas estruturas armazenadoras, permitindo o direcionamento das práticas de higienização e de outras estratégias de manejo para preservar a qualidade do milho armazenado.
\end{abstract}

Palavras-chave: monitoramento; armazenamento; pragas de produtos armazenados

\begin{abstract}
The study describes the spatial distribution of the stored grain beetles Sitophilus zeamais (Coleoptera: Curculionidae) and Oryzaephilus surinamensis (Coleoptera: Silvanidae) collected in a corn storage facility, including the receiving and drying areas, during August 2001 to June 2002 in Videira, State of Santa Catarina, Brazil. The experiment was composed by 20 food-baited cage traps, randomly placed in the storage structure, in order to detect spots of insect infestations. A total of 77,176 insects were captured in the food-baited traps. The most abundant species were: 0 . surinamensis (92\%) considered a secondary pest and S. zeamais (7\%), which is a primary pest. Monthly the spatial distribution of the insects collected was determined and represented in graphs of seasonal distribution (four seasons) using Surfer ${ }^{\circledR}$ software. The distribution maps indicated infestation of $S$. zeamais in the distal areas of the storage cells and high infestation of $O$. surinamensis, in proximal areas of the storage cells and in the tunnel of the storage structure. This way, the monitoring with cage traps and the use of spatial distribution maps represent an indispensable tool for the previous detection of insect populations in storage structures, allowing the management of cleaning and other handling strategies to preserve the quality of the stored corn.
\end{abstract}

Key-words: monitoring; storage; stored grain pests 


\section{INTRODUÇÃO}

Os coleópteros pragas de grãos armazenados têm grande importância econômica, pois, dependendo do nível de infestação, podem causar sérios danos quantitativos e qualitativos aos produtos que atacam. As infestações podem ocorrer antes da colheita, no transporte dos grãos e durante a armazenagem, seja ela em silos metálicos, de concreto ou graneleiros (Mills, 1995; Trematerra \& Fiorilli, 2000).

Várias ferramentas estão disponíveis para o manejo de insetos-praga de grãos e produtos armazenados. O conceito de manejo integrado de pragas (MIP) enfatiza a integração de medidas de controle, incluindo o uso de inimigos naturais, o manejo cultural, a sanitização e a correta utilização de pesticidas, dentro de um sistema amplo de manejo. O fundamento da técnica aponta para o controle das pragas antes de atingirem o nível de dano econômico, compreendendo as interações ecológicas dos insetos-praga e seu ambiente (Trematerra et al., 2004). Programas de MIP são adotados por várias indústrias de alimentos (Hagstrum \& Flinn, 1996). Porém no Brasil, a indústria de alimentos deve adotar os programas de MIP mais extensivamente, para satisfazer o aumento da demanda dos consumidores e agências reguladoras para o uso de inseticidas.

O manejo integrado de pragas de grãos armazenados em silos ou armazéns deve ser entendido como um processo conduzido em um ecossistema peculiar, relativamente fechado, em que o conhecimento do comportamento e da biologia das espécies, bem como dos fatores que regulam suas populações é o principal componente. O monitoramento das infestações de insetos deve ser constante e é um dos fundamentos do MIP, cuja ação prevê o uso de técnicas que geram informações precisas sobre a presença e flutuação de insetos para a tomada de decisão sobre quais medidas de controle são as mais adequadas (Dowdy \& Mcgaughey, 1994).

A armadilha tipo gaiola com isca alimentar é uma importante ferramenta para detectar a presença dos insetos na estrutura de armazenagem e já foi utilizada com sucesso no monitoramento da atividade dos insetos (Throne \& Cline, 1994). As principais razões para o uso de armadilhas para o monitoramento de insetos são: a detecção precoce de pragas, antes mesmo de serem encontradas por inspeção visual ou antes que existam evidências de dano; o monitoramento do número de insetos para determinar os níveis de captura que possibilitem ações de controle e o levantamento do número de infestações, visando quantificar o número de insetos capturados e identificação das espécies encontradas ao longo do ano na área de amostragem, possibilitando a realização de testes de resistência ou avaliando práticas de controle (Pinniger, 1990). Desta maneira, esta técnica de monitoramento pode gerar informações sobre a presença de pragas na área e servir como indicativo para proceder à amostragem direta de insetos na massa de grãos (Dowdy \& Mcgaughey, 1994).

A introdução da análise espacial e temporal na entomologia aplicada abriu novas possibilidades para o estudo e manejo da distribuição dos insetos de grãos armazenados em moinhos, silos e armazéns. Esta análise tem sido usada para estabelecer a técnica de monitoramento e métodos de controle preciso contra várias pragas de grãos armazenados (Sciarretta et al., 2001).

A análise da distribuição espacial dos insetos de grãos armazenados, com o uso de armadilhas, permite determinar quais são as principais áreas de risco em função do número de insetos capturados dentro da estrutura armazenadora. Esses locais deverão ser inspecionados e medidas de higienização ou controle químico e/ou físico dos insetos deverão ser realizadas.

Os dados obtidos a partir das coletas com as armadilhas e o mapeamento da distribuição espacial dos insetos proporcionam informações importantes para a elaboração de mapas de risco, os quais são úteis em programas de manejo integrado de pragas, permitindo direcionar medidas preventivas, como a limpeza da estrutura e maquinário e até medidas de controle das populações residuais, com a redução considerável dos produtos químicos normalmente aplicados em grãos armazenados.

O objetivo deste trabalho foi identificar as espécies de coleópteros de grãos armazenados predominantes em estrutura armazenadora de milho, estabelecendo a distribuição espacial e a sazonalidade da captura de indivíduos nas condições climáticas das quatro estações do ano.

\section{MATERIALE MÉTODOS}

O monitoramento dos coleópteros foi realizado em armazém graneleiro com fundo em "V", contendo milho, incluindo as áreas de recebimento e secagem dos grãos e três células de armazenagem com capacidade total de $12.000 \mathrm{t}$ (Figura 1). As coletas foram realizadas mensalmente no período de agosto de 2001 a junho de 2002.

Para detectar focos de insetos na estrutura armazenadora, foram utilizadas 20 armadilhas tipo gaiola, contendo atrativo alimentar, em uma modificação da metodologia usada por Strong (1970), Throne \& Cline (1991) e Pereira (1999). A estrutura das armadilhas foi construída em madeira (22 cm de largura $\times 30 \mathrm{~cm}$ de comprimento $\times 15 \mathrm{~cm}$ de altura) e coberta com uma chapa de ferro galvanizado, em forma de telhado, com a finalidade de proteger a isca alimentar da exposição direta ao tempo. Nas laterais da estrutura de madeira, foi colocada uma malha metálica de $3 \mathrm{~mm}$ com o objetivo de permitir a livre entrada de insetos, mas evitar o ataque de outros organismos, como pássaros e roedores. O atrativo alimentar era composto de uma mistura de grãos de milho, trigo, quirera de milho e germe de trigo, na proporção (em 


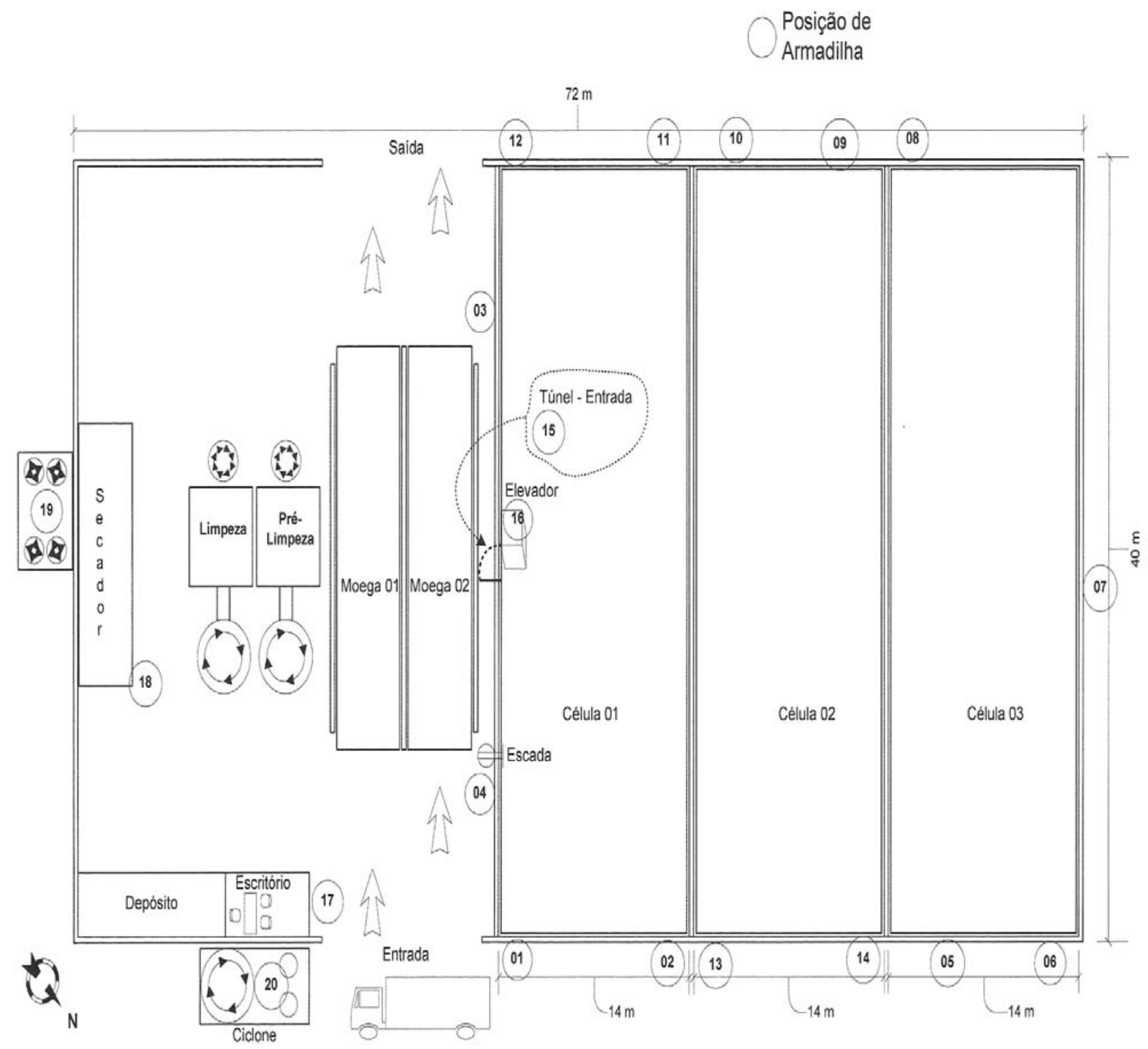

FIGURA 1 - Planta baixa da estrutura armazenadora de milho com a distribuição das armadilhas, utilizadas no monitoramento de insetos, no período de agosto de 2001 a junho de 2002 em Videira - SC.

massa) de $1: 1: 1: 0,5$, respectivamente, sem contaminantes. Essa mistura foi armazenada em freezer até o uso, colocando-se $200 \mathrm{~g}$ em cada armadilha.

As armadilhas foram distribuídas na unidade armazenadora conforme a Figura 1. As armadilhas tipo gaiola numeradas de 1 a 14 foram colocadas fora das células, no chão junto às paredes do graneleiro, a armadilha $n^{\circ} 15$ no túnel e a $n^{\circ} 16$ no elevador do graneleiro, as armadilhas $n^{\circ} 17$ e $n^{\circ}$ 20 na entrada da estrutura de armazenamento e as armadilhas $n^{\circ} 18$ e $n^{\circ} 19$ colocadas próximo ao secador.

Mensalmente, o atrativo era retirado da armadilha e levado ao laboratório para a contagem e identificação dos insetos. As armadilhas eram recolocadas no lugar com a reposição do atrativo alimentar.
Os dados de temperatura e umidade relativa do ar foram obtidos mensalmente na estação meteorológica da indústria, distante $100 \mathrm{~m}$ da estrutura de armazenagem.

Para a análise da distribuição espacial dos coleópteros capturados nas armadilhas foi utilizado o programa Surfer ${ }^{\circledR} 6.04$ da Golden Software. Os mapas da distribuição espacial das diferentes espécies foram confeccionados baseando-se nas estações do ano, representando as seguintes datas de coletas: 17/08 e 14/09/01 (inverno), 19/10, 19/11 e 17/12/01 (primavera), 07/01, 12/02 e 19/03/02 (verão), 22/04, 20/05 e 17/06/02 (outono).

No programa Surfer ${ }^{\circledR}, x$ e y representam as coordenadas da posição da armadilha dentro do silo em metros, e $z$ o número de insetos capturados. Pela interpolação dos valores de $z$, o Surfer ${ }^{\circledR}$ produz um denso grid de valores. O algoritmo de 
interpolação utilizado foi o kriging linear. O grid de interpolação obtido é usado para construir um mapa de contorno, que mostra a configuração da superfície por isolinhas representando os valores de z.

O Surfer ${ }^{\circledR}$ possui diversos métodos de interpolação dos dados, sendo o kriging o algoritmo mais utilizado para número de amostras entre $10 \mathrm{e}$ 250 , que neste trabalho consistiu de cada armadilha tipo gaiola em cada dia de coleta.

\section{RESULTADOS E DISCUSSÃO}

Foi capturado um total de 76.931 coleópteros de grãos armazenados no armazém graneleiro de milho. As espécies capturadas neste trabalho estão discriminadas na Tabela 1 , sendo observada a predominância de Oryzaephilus surinamensis, representando $92 \%$ e Sitophilus zeamais, com $7 \%$ do total de insetos capturados.

TABELA 1 - Número total de coleópteros de diferentes famílias, capturados com 20 armadilhas tipo gaiola, em armazém graneleiro de milho, em Videira - SC, no período de agosto de 2001 a julho de 2002.

\begin{tabular}{llc}
\hline Família & Espécie & $\mathrm{N}^{\circ}$ insetos capturados \\
\hline Silvanidae & Oryzaephilus surinamensis & 70657 \\
Curculionidae & Sitophilus zeamais & 5248 \\
Tenebrionidae & Tribolium castaneum & 750 \\
& Gnathocerus cornutus & 42 \\
Bostrichidae & Rhyzopertha dominica & 114 \\
Nitidulidae & Carpophilus spp. & 92 \\
Cucujidae & Cryptolestes ferrugineus & 28 \\
\hline
\end{tabular}

Empiricamente, observa-se na Figura 2 que o maior número de capturas, em seqüência, ocorreu nas armadilhas 10,14, 2, 13 e 11, localizadas na parede do graneleiro, junto às células de armazenamento de milho; diferindo das observações de Pereira (1999), Paula (2001) e Rupp (2001), que constataram que as armadilhas colocadas próximo dos locais de maior movimentação dos grãos, como moega e secador, foram as que mais capturaram insetos.
As capturas com armadilhas do tipo gaiola indicaram uma infestação expressiva de $O$. surinamensis, principalmente nas células de armazenagem, e de $S$. zeamais, indicando a necessidade urgente de higienização da estrutura e controle direcionado a estas espécies. A partir de focos de infestação, as espécies podem espalharse pela estrutura e infestar novos locais onde haja resíduos de grãos, requerendo monitoramento contínuo.

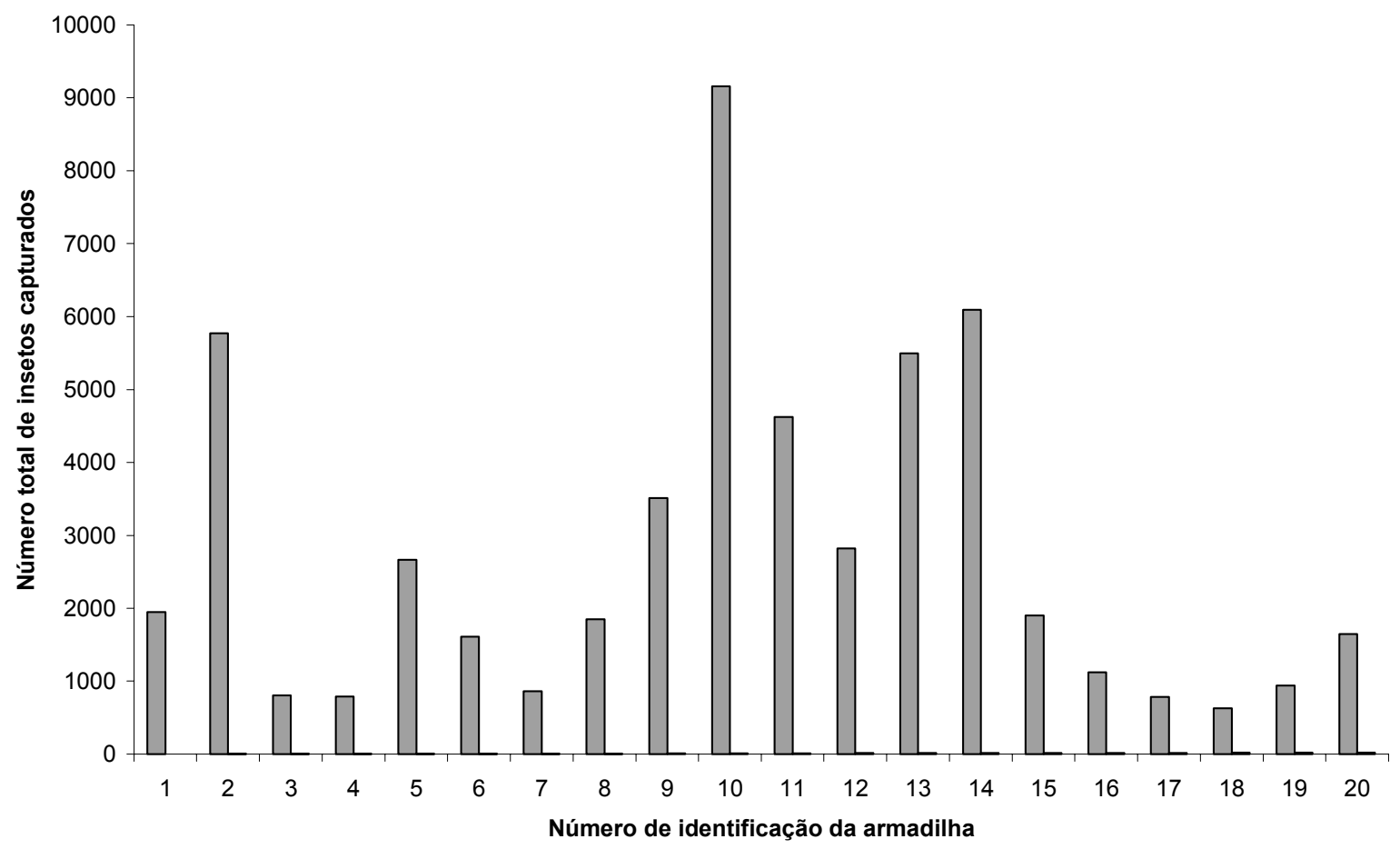

FIGURA 2 - Número total de coleópteros capturados em 20 armadilhas tipo gaiola com atrativo alimentar, em armazém graneleiro contendo milho, no período de agosto de 2001 a junho de 2002 em Videira $-\mathrm{SC}$. 
A espécie predominante $O$. surinamensis é cosmopolita e ataca grãos de cereais, farinhas, condimentos, castanhas, copra, frutos secos, macarrão, chocolate e até carnes secas (Dobie et al., 1984; Gallo et al., 2002). É considerada praga secundária, pois é incapaz de atacar grãos inteiros e sadios, preferindo grãos já infestados ou defeituosos, consumindo preferencialmente a região do embrião, podendo, no entanto, completar o desenvolvimento alimentando-se somente do endosperma.

A intensa captura da espécie $O$. surinamensis está de acordo com Pereira (1999), que capturou um número elevado de $O$. surinamensis em uma unidade armazenadora de milho em Guarapuava - PR, principalmente em locais próximos a depósitos de resíduos que possibilitavam a multiplicação desta espécie.

A ocorrência freqüente de $S$. zeamais na unidade armazenadora observada neste trabalho também foi observada por Pereira et al. (2000) e Pinto $\mathrm{Jr}$. et al. (2005), onde S. zeamais representou $63,4 \%$ e $59,8 \%$ dos insetos coletados nas armadilhas respectivamente.

Em adição, Pereira (1999), em um monitoramento com armadilhas tipo gaiola, verificou um pico de atividade dos insetos nos meses mais quentes do ano, quando a temperatura média estava entre 17 e $20^{\circ} \mathrm{C}$. Apesar de o número de insetos capturados nos meses mais frios terem sido baixo, o autor mostra que todas as espécies estavam ativas durante todo o ano, fazendo com que os grãos armazenados estivessem continuamente sujeitos à infestação.

$\mathrm{Na}$ análise da distribuição espacial de $S$. zeamais no armazém graneleiro de milho, verificou-se a presença dessa espécie mais afastada das células de armazenamento de milho (Figura 3), sendo que na região da entrada dos caminhões no armazém e próximo ao secador foram onde as armadilhas tipo gaiola coletaram o maior número de $S$. zeamais. As áreas de coloração preta mais intensa registradas nos mapas de distribuição, correspondentes à maior captura de $S$. zeamais, foram aquelas onde havia in loco a presença de grãos e resíduos espalhados pelo chão e sacarias acumuladas; mostrando que as áreas de maior movimentação de grãos ou mais sujeitas ao depósito de resíduos, representam potenciais focos de infestação de insetos para a massa de grãos e devem receber maior atenção dentro de um programa de manejo de pragas.

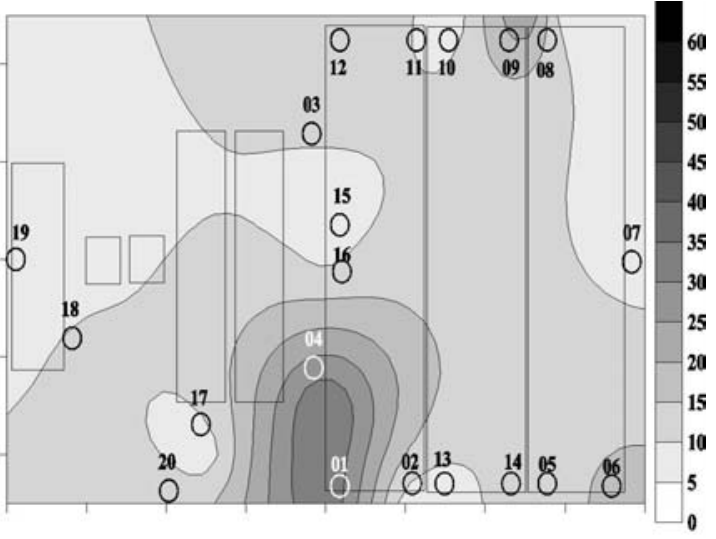

A.

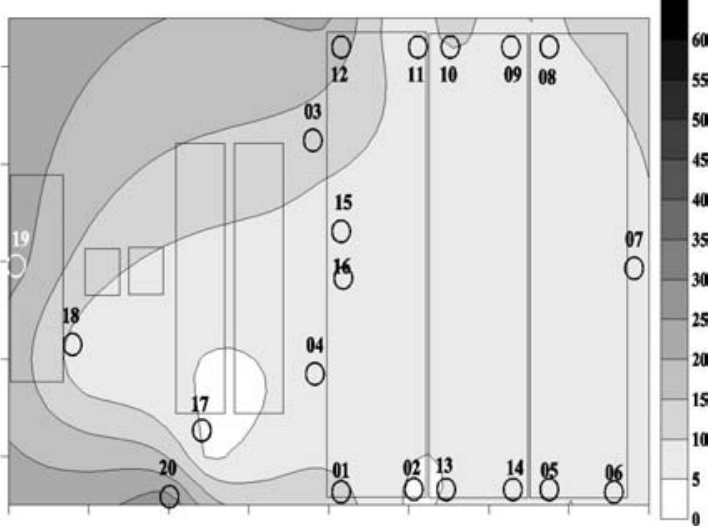

C.

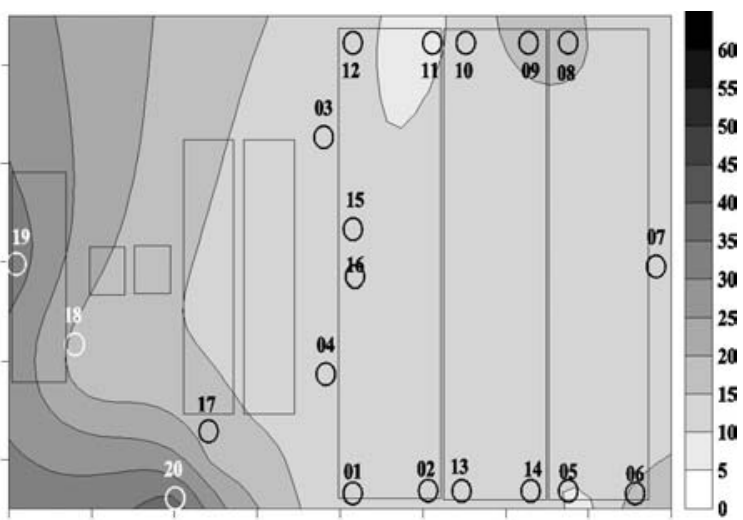

B.

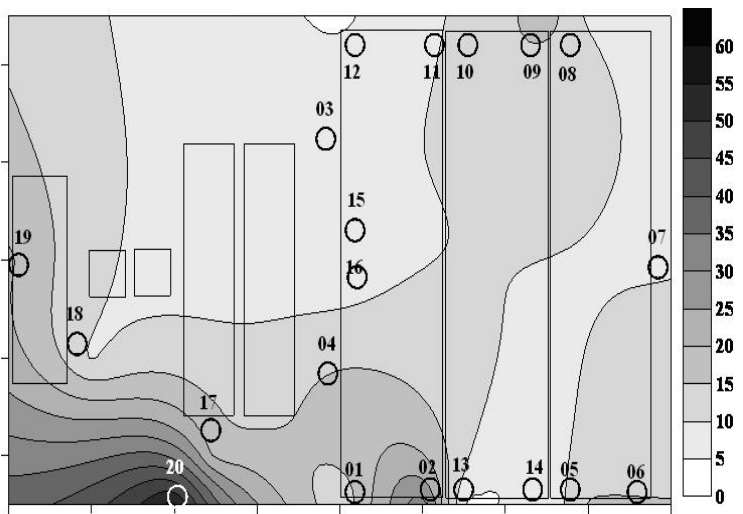

D.

FIGURA 3 - Distribuição espacial de $S$. zeamais na planta baixa do armazém graneleiro contendo milho. Os círculos representam as armadilhas tipo gaiola. A escala ao lado das figuras representa o número de insetos coletados nas armadilhas. A. inverno; B. primavera; C. verão e D. outono em Videira SC. 
$\mathrm{Na}$ análise de $\mathrm{O}$. surinamensis a distribuição espacial revelou a ocorrência junto às células de armazenamento de milho (Figura 4). As áreas em preto, registradas nos mapas de distribuição, foram

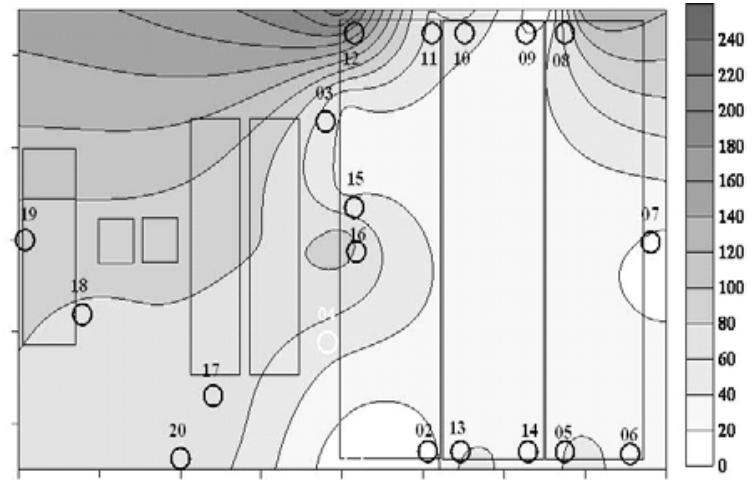

A.

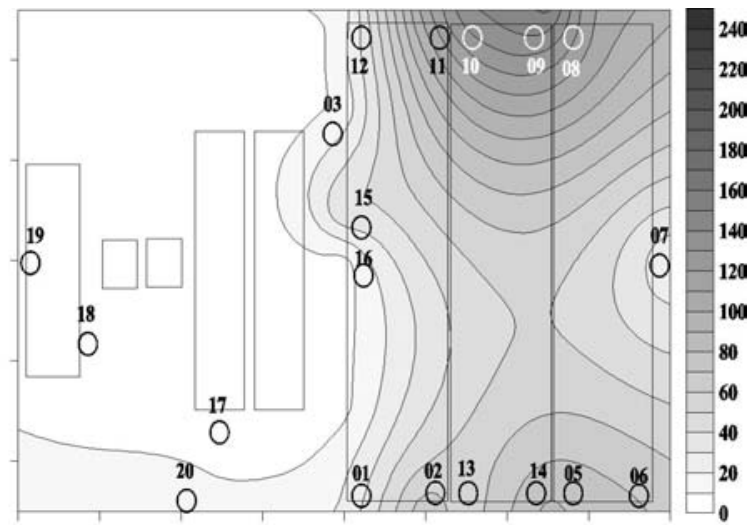

C. aquelas onde o inseto foi encontrado em maior número, principalmente nas paredes externas do graneleiro e no túnel, onde foram observados in loco muitos resíduos de grãos espalhados.

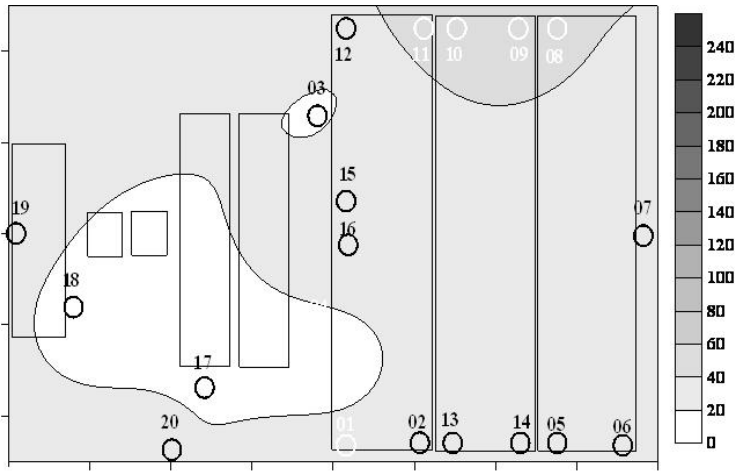

B.

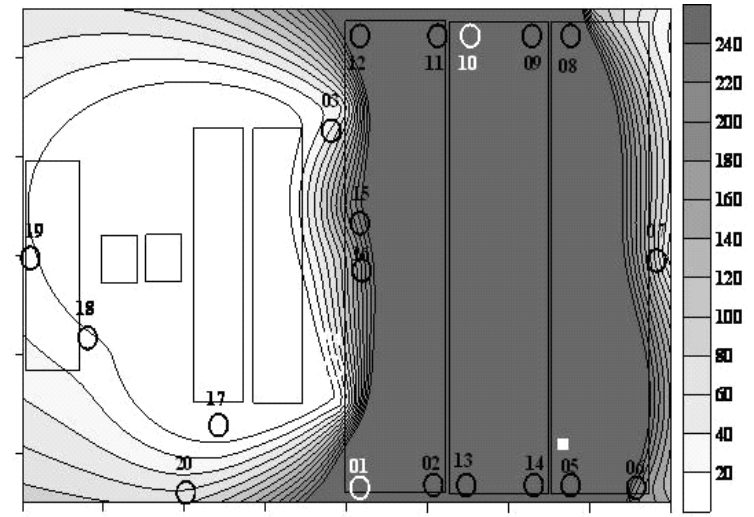

D.

FIGURA 4 - Distribuição espacial de O. surinamensis na planta baixa do armazém graneleiro contendo milho. Os círculos representam as armadilhas tipo gaiola. A escala ao lado das figuras representa o número de insetos coletados nas armadilhas (os valores plotados no mapa foram divididos por 10 , na figura D os valores foram multiplicados por 10). A. inverno; B. primavera; C. verão e D. outono em Videira - SC.

Santos et al. (2003) identificaram a região circunvizinha à parede do silo, como a faixa mais representativa para a coleta dos insetos pragas de produtos armazenados indicando, portanto, ser este - local para se realizar o processo de monitoramento. Em adição, informam que a redução do número de amostras de grãos, necessárias à determinação do grau de infestação, ocorre à medida que aumenta a densidade populacional de $S$. zeamais e que um sistema de amostragem seqüencial reduz os esforços amostrais.

Uma vez determinadas as áreas de maior incidência de insetos de produtos armazenados, buscam-se as prováveis causas da infestação, fazendo-se uma análise detalhada do local, observando desde os aspectos de higienização da estrutura, presença de resíduos de grãos, madeira em decomposição e sementes de plantas não cultivadas.

Vários fatores influenciaram a distribuição sazonal dos insetos ao longo do período de realização do trabalho de pesquisa na estrutura. No decorrer do ano várias atividades são realizadas como o recebimento de grãos e a expedição dos produtos que foram armazenados e, além disso, há variação de temperatura no decorrer das estações do ano. Estes fatores modificam os focos de infestação na estrutura como pode ser observado nas Figuras 3 e 4 e são fatores importantes nos programas de monitoramento, uma vez que diferentes ações são necessárias no mesmo local no decorrer das estações do ano ou das atividades realizadas nas estruturas de armazenamento.

Os resultados obtidos durante o período de 11 meses de coleta forneceram subsídios para a implantação de um programa de manejo integrado de pragas na unidade em questão. Com os mapas de distribuição, pode-se determinar os locais que necessitavam de maior atenção para a aplicação correta das práticas de manejo integrado na estrutura, com uso mais racional dos recursos disponíveis. 


\section{CONCLUSÕES}

1) O. surinamensis é o coleóptero de grãos armazenados predominante em estrutura armazenadora de milho em Videira, SC. Ocorre nas áreas proximais às células de armazenamento de milho, com maior intensidade no outono.

2) S. zeamais é a segunda espécie predominante em estrutura armazenadora de milho, ocorrendo nas áreas distais às células de armazenagem, onde há movimentação de grãos, com maior intensidade no verão.

\section{REFERÊNCIAS}

1. $\mathrm{DOBIE}, \mathrm{P}$. et al. Insects and arachnids of tropical stored products, their biology and identification: a training manual. London: Tropical Development and Research Institute, 1984. 273 p.

2. DOWDY, A. K.; MCGAUGHEY, W. H. Seasonal activity of stored product insects in and around farm-stored wheat. Journal of Economic Entomology, v. 87, n. 4, p. 1352-1358, 1994.

3. GALLO, D.; et al. Entomologia agrícola. Piracicaba: Fundação de Estudos Agrários Luiz de Queiroz - FEALQ, 2002. $920 \mathrm{p}$.

4. HAGSTRUM, D. W.; FLINN, P. W. Ecology. In: SUBRAMANYAM, B., HAGSTRUM, D. W. Eds. Integrated management of insects in stored products. New York: Marcel Dekker 1996. p. 71-134.

5. MILLS, J. T. Ecological aspects of feed-mill operation. In: JAYAS, D. S.; WHITE, N. D. G.; MUIR, W. E. Eds., Stored grain ecosystems. New York: Marcel Dekker, 1995. p. 677-707.

6. PAULA, M. C. Z. Manutenção da qualidade do arroz armazenado: monitoramento e controle de insetos. 2001. 74 f. Tese (Doutorado em Entomologia) - Curso de Pós-Graduação em Entomologia, Setor de Ciências Biológicas, Universidade Federal do Paraná, Curitiba, 1999.

7. PEREIRA, P. R. V. S. Contribuição para o manejo integrado de pragas de produtos armazenados. $1999.99 \mathrm{f}$. Tese (Doutorado em Entomologia) - Curso de Pós-Graduação em Entomologia, Setor de Ciências Biológicas, Universidade Federal do Paraná, Curitiba, 1999.

8. PEREIRA, P. R. V. S.; LAZZARI, F.; LAZZARI, S. M. N. Insect monitoring outside grain storage facilities in southern Brazil. In: PROCEEDINGS $7^{\text {TH }}$ INTERNATIONAL WORKING CONFERENCE ON STORED-PRODUCTS PROTECTION, 1., 2000, São Paulo. Anais. São Paulo: ABRAPÓS, 2000. p. 1534-1536.

9. PINNIGER, D. B. Food-baited traps: past, present and future. Journal of the Kansas Entomological Society, v. 63, n. 4, p. 533-538, 1990.

10. PINTO JR., A. R.; CERUTI, F. C.; WEBER, S. H. Monitoramento de insetos em estrutura armazenadora através de armadilha com atrativo alimentar localizada fora dos silos. Revista Acadêmica (PUC - PR), v. 3, n. 1, p. 35-41, 2005.

11. RUPP, M. M. M. Avaliação de formulações de pós - inertes no controle de insetos em cevada cervejeira e malte armazenados. 2001. 92 f. Tese (Doutorado em Entomologia) - Curso de Pós-Graduação em Entomologia, Setor de Ciências Biológicas, Universidade Federal do Paraná, Curitiba, 2001.

12. SANTOS, A. K., et al. Distribuição e amostragem de Sitophilus zeamais (M.) em grãos de trigo armazenado em silo metálico. Revista Brasileira de Engenharia Agrícola e Ambiental, v. 7, n. 3, p. $505-512,2003$.

13. SCIARETTA, A.; TREMATERRA, P.; BAUMGÄRTNER, J. Geostatistical analysis of Cydia funebrana (Treitschke) (Lepidóptera: Tortricidae) pheromone trap catches at two spatial scales. American Entomologist, v. 47, n. 1, p. 138-147, 2001.

14. STRONG, R. G. Distribution and relative abundance of stored products insects in California: a method of obtaining sample populations. Journal of Economic Entomology, v. 63, n. 2, p. 591-596, 1970.

15. THRONE, J. E.; CLINE, L. D. Seasonal abundance of maize and rice weevils (Coleoptera: Curculionidae) in South Carolina. Journal of Agricultural Entomology, v. 8, n. 1, p. 93-100, 1991.

16. THRONE, J. E.; CLINE, L. D. Seasonal flight activity and seasonal abundance of selected stored-product Coleoptera around grain storages in South America. Journal of Agricultural Entomology, v. 11, n. 3, p. 321-338, 1994.

17. TREMATERRA, P.; FIORILLI, F. Stored-product insects pests in feed-mill in Central Italy. IOBC wprs Bulletin, v. 23, n. 1, p. 103-109, 2000.

18. TREMATERRA, et al. Spatio-temporal analysis of insect pests infesting a paddy rice storage facility. Neotropical Entomology, v. 33, n. 4, p. 469-479. 2004. 
